\title{
A Commentary on the Social Perspective on Creativity
}

\author{
Mark A. Runco \\ University of Georgia, Athens, GA USA \\ E-mail address: runco@uga.edu
}

ARTICLE INFO

\section{Keywords:}

Potential

Parsimony

Divergent thinking

\section{Article history:}

Received 3 December 2014

Received in revised form 18 December 2014

Accepted 21 December 2014

ISSN: 2354-0036

DOI: 10.1515/ctra-2015-0003

\section{A B STRACT}

This commentary examines the social perspective on creativity, as presented in the featured article. There are several attractive aspects to the social perspective, but serious limitations as well, which are detailed in this commentary. The assumptions of the social perspective are also discussed. The most questionable of these assumes that social recognition and impact are inherent parts of creativity. The parsimonious alternative is to define creativity such that it includes only what is related to creativity per se and to recognize that social recognition may follow creation and is certainly extricable from it. A defence of this parsimonious view is presented. A brief discussion of possible crises in the field of creativity studies is also presented, with one suggestion being that the diverse approaches used in the field represent a kind of divergent thinking and as such represent progress, even though it is not linear. This commentary concludes with a discussion about creativity being vital for quality of life. That perspective differs dramatically from the product view of creativity which is often tied to a social perspective.

\section{A Commentary on the Social Perspective on Creativity}

There are many positive aspects to Glăveanu's (2014) featured article. It is a wellresearched, well-written overview. I especially appreciate his view that research should be explicitly connected to underlying theories and models. I would add a caveat that a model is just a model, however, and I disagree with the claim that the psychology of creativity is in - or close to - a crisis. I have now edited the Creativity Research Journal for 27 years, and I have seen tremendous progress, especially as of late. Lately the disciplinary boundaries have been dissolving, for instance, and perspectives on creativity have been enriched, just to name one reason for optimism.

This commentary explores the optimistic view of progress in the field of creativity studies. Most important is the discussion herein of Glăveanu's assumptions, and in particular his emphasis on the social requirements of creativity. I devote most of this commentary 
to problems with this emphasis. Some of these are well known. Indeed, they were directed at Kasof's (1995) article, featured in the Creativity Research Journal and focused on the attributional theory of creativity. The attributional perspective holds the same key assumptions as Glăveanu, many of which were questioned by the commentaries published in response to Kasof (1995), (e.g., Albert, 1995; Amabile, 1995; Sternberg, 1995; Runco, 1995). I do not devote pages of the present commentary to merely repeating the obvious criticisms of the social definition of creativity, however. More recent research is presented here. Simonton (2012) and Weisberg (in press) have gone to some length to update the standard definition of creativity (Runco \& Jaeger, 2012), for example, and I have continued to defend the view of personal creativity and build the parsimonious theory of creativity, and both are useful counterpoints to the social view of Glăveanu.

The material summarized here helps to put the social view of creativity in its place. I use that particular wording to avoid suggesting that the social view is worthless. No one completely dismisses social influences on the creative process, nor social ramifications of the creative process. As we will see below, that is what they are, however, influences and ramifications. As such they are extricable from creativity. The social perspective has its place, but it should not be exaggerated.

\section{A Crisis?}

Glăveanu seems to have foreseen questions over whether or not there is in fact a crisis in the creativity research, which is good scholarship on his part. I am not certain, however, that he recognized the assumptions underlying the argument for a crisis. One key assumption is that we should be concerned about "fragmentation and dispersion" in the research. Certainly those two things sound bad, and very well might be, but on the other hand dispersion could easily be indicative of divergent thinking, and this in turn implies that it might eventually lead to a creative breakthrough. I have been quite explicit that divergent thinking is by no means synonymous with creativity (Runco, 1991, 2013), but divergent thinking is a good indicator of the potential for creative thinking. More generally, it is quite possible that research should show divergence and dispersion. Fragmentation is more likely to be a problem, but it might be a necessary evil, given the need for dispersion. There may be advantages to fragmentation, just as there are to dispersion. Fragmentation could motivate or drive research towards integration and thus may be an influence on progress, just to mention one possibility.

At about the same point in his presentation, Glăveanu raises the question, "what is the field developing towards?" This too is worrisome. Surely that assumes a kind of teleological approach that no one who believes in evolution as progress would accept. Instead 
of developing towards a particular direction we should appreciate divergence and the exploration and focus on a worthwhile process, rather than picking a goal and trying to work towards it. I may be sensitive to everything that hints at an agenda, but there are reasons for this. First is the practical problem where decision-makers claim to value creativity and innovation, but do not actually support them. This may result from ignorance or duplicity. Both are apparent at different times. Ignorance occurs when creativity and innovation are simply misunderstood. In fact, divergent thinking can again be cited: often it is tied to creativity, and for that reason people state, "divergent thinking will be supported" (e.g., in the classroom, business organization, or culture). But then wild and original ideas are presented, and the tune changes. Those original ideas are weird! The truth of the matter is that, to support creativity, you need tolerance. You need to accept unconventional ideas, even if you do not understand them or see their value. The creative process is not teleological. You either open up to originality, divergence, and possibility, and perhaps find a creative idea or breakthrough, or you target and focus and probably miss the most original options.

\section{Creativity Defined}

Glăveanu states that "the most important part of creativity" is "the reconstruction of this work, symbolic and material, when perceived and used by others. Without this ability to make existing things new by reworking our understanding of them and relation to them, the Mona Lisa would simply be today an old, well crafted painting."

There are several problems with a social view of creativity. One follows from the fact that the word "creativity" is inextricable from "creation" (or "to create"), which in turn implies that something new is brought into being. This is easily extricable from "reconstruction" by others. Additionally, creativity need not lead to implementation. It need not be judged or labeled creative. If it is socially recognized, there may be a consensus about it, which can be a good thing. This could even be indicative of inter-judge reliability. There is no guarantee that there would be long-term reliability, however, and in fact opinions of creativity vary from era to era. How can that happen? A human capacity, such as creativity, doesn't vary through history. What varies is opinion (Weisberg, in press). To make matters worse, the consensus and social recognition is likely to be biased by salience or values. No wonder judgments of creative people and products vary from era to era. In fact, there are all kinds of differences among judges who are asked to rate potentially creative products (Runco, 1989; 1999; Runco, McCarthy \& Svensen,1994; Runco \& Smith, 1992) and significant differences even among experts. These differences among experts are quite clear in analyses of encyclopedias and the like, 
which show that reputations of famous "creators" vary dramatically from era to era (and volume to volume) (Runco et al., 2010). Such variation can be taken as indicative of a lack of inter-rater reliability, which in turn implies that the social definition is not objective nor scientifically acceptable. Most convincing may be the fact that there are words for social recognition: fame and reputation come to mind (Runco, 1995). Clearly social recognition is achieved for various reasons, and sometimes it has nothing to do with creativity.

None of this implies that creativity is unrelated to social processes and contexts. There are social influences on creativity, and creativity sometimes has social ramifications. The only claim being made here is that creativity does not depend on social recognition. Creativity is one thing, social recognition something else. So what is creativity, if it is extricable from social recognition?

A recent definition of parsimonious creativity goes into detail about the separation of "mere influences" and the universal requirements of creativity. The former include personality, attitude, culture, development, and motivation. These can have a significant impact on the creative process, creative potential, and the creative capacity, but their existence does not guarantee creativity. They are, then, influences. Even motivation, which could be connected to nearly all human behaviors, does not qualify as required for creativity, given that some individuals might be highly motivated but remain unoriginal, and thus uncreative. In addition, motivation is not a unitary thing, and sometimes intrinsic motivation seems to lead to creative performance, but other times extrinsic motivation is more clearly involved, and yet other times both are apparent (Amabile \& Kramer, 2010; Eisenberger \& Shanock, 2003; Rubenson \& Runco, 1992; Runco, 2008). Then there are suggestions of serendipity and accidental discoveries or unconscious contributions to creative insight, which also make it difficult to weigh motivation as universally required for all creativity.

Motivation is just being used as an example of something that is recognized as part of the "creativity complex" or "creativity syndrome" but is actually just an influence, and thus only vital some of the time. Several other components of the creativity complex can also be examined carefully and found to be unnecessary. They may be involved some of the time, but they are not always involved, no doubt because they are "mere influence" and not absolute requirements. This distinction between influences and requirement is especially relevant to any effort to identify the mechanism that explains the creative process, creative potential, or the creative capacity (Jay \& Perkins, 1999). A scientific explanation of creativity needs a mechanism. It needs to pinpoint causes, not correlates and influences. 
One aspect of parsimonious creativity categorizes motivation and those other things are "mere influences" which sometimes precede actual creation. A second aspect of parsimonious creativity identifies results or effects that are also not universal and shared by all creative performances, and as such should be seen as sometimes correlated with creativity but not vital. Productivity might be a good example of such a possible result. Creative efforts often lead to a product, but not always. Certainly it depends on how you define "product." If ideas and insights are products, then there is always a product, but then you need to recognize that ideas take many forms. They are far from universal. A dancer uses one kind of idea, a mathematician another, and a chef yet another. Recall here that there is some sort of creation in creativity, but it need not be a tangible product, nor a socially-recognized product. It may be a personal product, such as an idea, insight, original interpretation of experience. It may give the individual meaning or allow effective action or adaptation. It could also lead to something that is shared publically. That can and does happen, but it is not vital for all creativity.

Simplifying some, there are (a) influences on creativity, (b) a mechanism which is required for the creativity, and (c) possible results of the creativity. In the last category you have social judgment, attributions, and the "reconstructions by others" that Glăveanu describes in his featured article. Only (b) is, however, required for creativity. Both (a) and (c) should be recognized as things that either precede or result from creativity, but since they are not vital to creativity, they should be kept out of a definition of creativity.

The theory of parsimonious creativity focuses on an actual mechanism and extricates correlates (i.e., mere influences and possible, but not guaranteed results). Also, it is nicely scientific in its emphasis on parsimony. This is in direct contrast to a social definition-and any definition that includes unnecessary influences or unnecessary effects. Parsimony is also relevant in that there are other labels for those extraneous things. Social judgment leads to reputation and, for high quality works, fame. Those are good useful words for the occasional effects of creativity, when people besides the creator reconstruct the value of the product or event. If creativity is defined so it includes social judgment (or any of the extraneous influences or effects), it is confounded by things which are not vital to creativity. It would be a bit like defining an automobile as a four-wheeled vehicle that always goes 200 miles per hour. Some cars do that, but not all of them do, and such speed is not vital for a car. So too can a person create without having judges reconstruct the interpretation. Even more simply, to say that recognition is a part of creativity is much like saying that winning a race is a part of driving.

Parsimonious creativity distinguishes between creativity and innovation. Innovation, 
even more than fame, is sometimes related to creativity, but it is not the same thing as creativity. Innovation differs from creativity either in (a) the ratio of originality - toeffectiveness (with originality more important in creativity and effectiveness more important for innovation), or in (b) what processes are involved, with innovation requiring an implementation or application "stage" of the process (Runco, 2014). You could say that creativity involves implementation, but there is a word for a creative endeavor that goes all the way and is sold, implemented, and applied. That word is "innovation" not "creativity." It is confusing to bring implementation into the creative process, just as it is to require social judgment (and in a word, "fame" or "reputation") or some possible effect of creation.

One last point about parsimonious creativity should be mentioned, in part because it says something more about the nature of creativity, and in part because it suggests a direction for future research. Recall here that only two things are required for creativity: the creation of something that is original and effectiveness (or value). If that original and effective idea eventually leads to social recognition, then fame, or more simply, social recognition also occurs. But the creativity requires only originality and effectiveness. And as it happens, the human mind is capable of multitasking; plenty of neuroanatomical and neurochemical research shows that various things happen in the brain simultaneously. Cognitive theories describe such multitasking as well. In fact, various theories of creative cognition emphasize some sort of multitasking. Theories of bisociation (Koestler, 1964), Janusian thinking (Rothenberg, 1999), and what is simply called "simultaneous processing" (Runco, 2010) each exemplify this.

Perhaps human creativity results from the simultaneous processing of originality and effectiveness. If so, it is really quite far from complex. It is, in fact, unitary. This would seem to fit nicely with evolutionary theories that describe an inborn capacity for coping with unexpected hassles and novel problems, for expressing ourselves in an original fashion, and sometimes, for sharing new things that other people see as creative.

\section{Creativity and Quality of Life}

Just as I do not agree that social recognition is required for creativity, so too would I question the necessity of combinations and recombinations as part of the creative process. Glăveanu (2014) proposed that

"In the end, nothing is truly absolute in the absolute sense of the word since, as we know, creative products don't emerge out of thin air, but out of the (re)combinations of whatever exists. In this regard, novelty and originality need to be evaluated in relation to socio-cultural background." 
I am not yet convinced that nothing is truly original in the absolute sense of the word, in part because, contrary to Glăveanu's assumption, creative things may not depend on combinations and recombinations. There are data showing that some creative things could possibly result from combinations and recombinations, but there are no data showing that actual creative insights have always depended on combination or recombination. It is much like the research showing that computers can discover scientific laws if given the right information. That just means that computers can do it; it does not prove that human creators went about creativity the same way. All we can say is that combination and recombination can lead to creative ideas, at least in controlled and artificial settings. Of course Glăveanu is correct that creative products do not emerge out of thin air, but there are possibilities besides combination and recombination (e.g., the inventions described by Piaget, or chaotic, blind, or truly divergent, nonlinear processes). In fact, I would not be surprised if we eventually understand the human mind well enough to see that true originality is feasible, or even commonplace. At that point anything that is a mere recombination would be relegated to a variation rather than an actual breakthrough.

Then there is that troubling assumption about products and about socio-cultural contexts. Glăveanu referred to the Mona Lisa and implied that the most important thing was that an audience was able to relate to the painting. The view presented here is that the Mona Lisa was important, independently of any audience or sales price. Recall here the idea that creativity may not lead to a tangible product. And yet there may be clear benefits. In fact, the non-tangible benefits may be the broadest and most wide-ranging. They include various aspects of quality of life. Creativity gives us so much, every day. It gives us pleasure, and sometimes puzzles and disturbance, all of which are a part of life. Creativity gives us rich, meaningful experiences. It adds to our experience, most obviously in an aesthetic way, but also in the sense that creative things keep us mindful and engaged. Think how boring life would be if, say, every street in our neighbourhood was named "Peachtree," or if every son in a family was named "Junior." Instead, we have Mark, Tommy, Achmed, Ethan, Nate, Chuck, and innumerable other options. The same thing is true of everything we experience; our originality adds richness. Richards (2007 , p. 290) seems to feel this way, for she had "observing actively" in her list of benefits of creativity. Richards also had bravery, development, androgyny, caring, dynamism, consciousness, health, a non-defensive capacity, openness, and integrations in her list of what a person does when he or she is living creatively.

The point is that creativity allows each of us to create meaning. Life needs meaning, and not everyone is lucky enough to be given a compelling meaning in life. For that mat- 
ter, is anyone given meaning in life? Very likely, each person's meaning must be constructed for him- or herself, or it will not be meaningful. Florida (2002) put it very well:

"Modern life is increasingly defined by contingent commitments. We progress from job to job with amazingly little concern or effort. Where people once found themselves bound together by social institutions and formed their identities in groups, a fundamental characteristic today is that we strive to create our own identities. It is this creation and recreation of the self, often in ways that reflect our creativity, that is the key feature of creative effort. In this new world, it is no longer the organizations we work for, churches, neighbourhoods, or even family ties that define us. Instead, we do this ourselves, defining our identity along the dimensions of our creativity" (p. 7).

Gruber (1988) and Barron (1995) were also quite explicit about creativity for quality of life. The humanistic view of creativity as inextricable from self-actualization is certainly relevant in this regard (Richards, 1991; Rogers, 1959; Runco, 2005), as is the argument that a universally-applicable definition of creativity must include authenticity (e.g., Kharkhurin, 2014).

In sum, creativity does not require a tangible product, nor an audience.

\section{Conclusions}

Glăveanu (2014) lamented the lack of research on definitions of creativity. He will no doubt therefore appreciate the recent efforts of Simonton (2012), Kharkhurin (2014), and Weisberg (in press). Each of these scholars goes into detail about the various dimensions of creativity (e.g., originality, value, effectiveness, authenticity). Glăveanu will also probably be pleasantly surprised if he reads more deeply about divergent thinking. His treatment of divergent thinking in the featured article was superficial, to put it mildly. Oddly, he quoted Torrance (1988) on the infinite and possibly extrasensory or unconscious nature of creativity. This is relevant because Torrance's thinking actually fits well with that of Gruber (1988), Barron (1995), Richards (2007), Rogers (1970), and Kharkhurin (2014), each of whom was cited above on the proposal that creativity is more than productivity; it is also key for quality of life.

Note, then, that Torrance saw creativity as playing a significant role in the quality of life and the creation of meaning. And yet Torrance did decades of research on divergent thinking! Glăveanu seems to see a contradiction. He wrote, "so we can legitimately ask, how is this experiential and ontological richness of creativity of a phenomenon ever contained in tasks like, 'please generate as many uses as possible for a brick'." That is nothing but a straw argument, which is why Torrance did see creativity as playing a far-reaching role in the meaning of life and yet, at the same time, recognized the value of divergent thinking. 
What Glăveanu ignores is that divergent thinking is not a definition of creativity. It is an estimate of the potential for creativity. Divergent thinking tasks offer reliable information about one of the things that allows some people to produce original ideas. If you think of divergent thinking in this fashion, it is not incompatible with the position above, that creativity contributes mightily to the quality of life, nor incompatible with Torrance's (1988) position. There is no contradiction at all. And there are data showing that, not only are certain tests of divergent thinking reliable; they are more predictive of creative performance that occur in the natural environment than is, say general or academic intelligence (Wallach \& Wing, 1969). The usefulness of the information provided by divergent thinking (as an estimate of the potential to produce original ideas) holds up over a 50 year period. Incidentally, this finding of the longitudinal predictive usefulness of divergent thinking is based on Torrance's own data (Runco, Cramond, Millar, Acar, 2011).

Glăveanu's review is, by and large, well done. He is not the first to expect too much of divergent thinking, and the contributions of his review clearly outweigh the concerns I have with it. It should be apparent that the major concerns with Glăveanu's featured article are reactions to his assumptions about creative products and social requirements. The teleology is also a concern, as is the disregard for a basic tenet of science, namely parsimony. Still, science is a collaborative effort, and with that in mind I would suggest that the featured article is worth reading, as an example of a social, product perspective (also see Runco, 2010; Simonton, 2010). Taken together the featured article, the present effort, and other commentaries found herein can contribute to a collaborative advance in our understanding of creativity.

\section{REFERENCES}

Albert, R. S. (1995). Madison Avenue Comes to Academe. Creativity Research Journal, 8, 427-429.

Amabile, T. M. (1995). Attributions of Creativity: What Are the Consequences? Creativity Research Journal 8, 423-426.

Amabile, T. M. (1985). Motivation and creativity: Effects of motivational orientation on creative writers. Journal of Personality and Social Psychology, 48, 393-399.

Amabile, T. M., \& Kramer, S. (2010). What really motivates workers. Harvard Business Review, 88, 1, 44-45.

Barron, F. (1995). No rootless flower: An ecology of creativity. Cresskill, NJ: Hampton Press. 
Eisenberger, R., \& Shanock, L. (2003). Reward, intrinsic motivation, and creativity: A case study of conceptual and methodological isolation. Creativity Research Journal, $15,121-130$.

Glăveanu, V. P. (2014). The psychology of creativity: A critical reading. Creativity. Theories - Research - Applications, 1, 10-32; DOI: 10.15290/ctra.2014.01.01.02.

Gruber, H. E. (1988). The evolving systems approach to creative work. Creativity Research Journal, 1, 27-51.

Kasof, J. (1995). Explaining creativity: The attributional perspective. Creativity Research Journal, 8, 311-366.

Kharkhurin, A. (2014). Creativity four-in-one: Four Criterion Construct of Creativity Creativity Research Journal, 26, 338-352.

Koestler, A. (1964). The act of creation. New York: Macmillan.

Richards, R. (1991). A new aesthetic for environmental awareness: Chaos theory, the beauty of nature, and our broader humanistic identity. Journal of Humanistic Psychology, 41, 59-95.

Richards, R. (2007). Everyday creativity and new views of human nature. Washington, DC: American Psychological Association.

Rogers, C. R. (1959). Toward a theory of creativity. In H. H. Anderson (Ed.), Creativity and its cultivation (pp. 69-82). New York: Harper \& Row.

Rothenberg, A. (1999). Janusian processes. In M. A. Runco \& S. Pritzker (Eds.), Encyclopedia of creativity (pp. 103-108). San Diego, CA: Academic.

Runco, M. A. (1989). The creativity of children's art. Child Study Journal, 19, 177-189.

Runco, M. A. (1995). Insight for creativity, expression for impact. Creativity Research Journal, 8, 377-390.

Runco, M. A. (1999). Misjudgment of creativity. In M. A. Runco \& S. Pritzker (Eds.), Encyclopedia of creativity (pp. 235-240). San Diego, CA: Academic Press.

Runco, M. A. (2005). Self-actualization. In N. J. Salkind (Ed.). Encyclopedia of human development (pp. 1132-1133). Thousand Oaks, CA: Sage Publications.

Runco, M. A. (2010). Creative thinking may be simultaneous as well as blind [Comment on Creative thought as blind-variation and selective retention: Combinatorial models of exceptional creativity by Dean Keith Simonton] Physics of Life Reviews, 7, 184-185.

Runco, M. A. (2010). Products depend on creative potential: A comment on the productivist industrial model of knowledge production. Gifted and Talented International, 25, 81-87.

Runco, M. A., \& Jaeger, G. (2012). The standard definition of creativity. Creativity Research Journal, 24, 92-96. 
Runco, M. A., McCarthy, K. A., \& Svensen, E. (1994). Judgments of the creativity of artwork from students and professional artists. Journal of Psychology, 128, 23-31.

Runco, M. A., \& Smith, W. R. (1992). Interpersonal and intrapersonal evaluations of creative ideas. Personality and Individual Differences, 13, 295-302.

Sternberg, R. J. (1995). If You Change Your Name to Mark Twain, Will You Be Judged As Creative? Creativity Research Journal, 8, 367-370.

Simonton, D. K. (2012). Taking the U.S. Patent Office Criteria Seriously: A Quantitative Three-Criterion Creativity Definition and Its Implications. Creativity Research Journal, 24, 97-106.

Wallach, M. A., \& Wing, C. W. Jr. (1969). The Talent Student: A Validation of the Creativity Intelligence Distinction. New York: Holt, Rinehart, \& Winston.

Corresponding author at: Mark A. Runco, Torrance Creativity Center, University of Georgia, Athens, 323 Aderhold Hall, Athens, GA 30602

E-mail: runco@uga.edu 